\title{
Visual outcome of ranibizumab therapy for neovascular age related macular degeneration in the black population: a report of five cases
}

This article was published in the following Dove Press journal:

Clinical Ophthalmology

6 August 2010

Number of times this article has been viewed

Roopa Vemala

Bhaskar Gupta

Sobha Sivaprasad

Laser and Retinal Research Unit, King's College Hospital, London SE5 9RS, UK
Correspondence: Sobha Sivaprasad King's College Hospital, Denmark Hill, London, SE5 9RS, UK

Tel +44 203299 I297

Fax +442032993738

Email senswathi@aol.com
Introduction: Neovascular age related macular degeneration (AMD) is relatively uncommon in the black population. We report the 12-month outcome of ranibizumab therapy in five black patients with choroidal neovascular membrane (CNV) secondary to AMD.

Material and methods: Retrospective analysis of a prospective audit database maintained for all patients on ranibizumab therapy in a retinal specialist unit that caters to a multi-ethnic cohort in London, United Kingdom.

Results: At 12 months, all the 5 patients maintained stable vision (loss of less than 15 ETDRS letters). However, none of them gained more than 15 ETDRS letters. All eyes showed early subretinal fibrosis while 2 patients showed extended areas of retinal pigment atrophy.

Conclusion: Our case studies indicate that ranibizumab stabilizes the vision in black patients with CNV secondary to AMD but they tend to develop early subretinal fibrosis and retinal pigment atrophy.

Keywords: choroidal neovascular membrane, Afro-Caribbean, blacks

\section{Introduction}

Neovascular age related macular degeneration (AMD) causes severe visual loss and is the most common cause of blindness in the western world. ${ }^{1}$ Population based epidemiological studies have shown significant variation in the prevalence of AMD among various racial/ethnic groups. ${ }^{2}$ Data from prevalence of AMD in 4 racial/ethnic groups in the multi-ethnic study of atherosclerosis suggested prevalences of AMD were $2.4 \%$ in blacks, $4.2 \%$ in Hispanics, $4.6 \%$ in Chinese and $5.4 \%$ in the white population, while estimated prevalence of late AMD were $0.3 \%$ in blacks, $0.2 \%$ in Hispanic, $0.6 \%$ in the white and $1.0 \%$ in the Chinese population. ${ }^{3}$ In contrast, the incidence of idiopathic polypoidal choroidopathy (PCV) is high among blacks, moderate in Asians and low in whites. ${ }^{4}$ Therefore, a high index of suspicion of both conditions are required when evaluating black patients with clinical presentation of AMD.

Ranibizumab is an inhibitor of all isoforms of VEGF-A. ${ }^{5}$ It has been shown to be effective in improving vision (gain of more than 15 letters) in subfoveal choroidal neovascularisation (CNV) secondary to neovascular AMD in several randomized trials in predominantly Caucasian cohorts. ${ }^{5,6}$ We report the clinical features and 12-month outcome of ranibizumab therapy in five black patients with neovascular AMD and no evidence of PCV on indocyanine angiography (ICGA). 


\section{Material and methods}

A prospective database is maintained for all patients on ranibizumab therapy in the Medical Retina clinic at King's College Hospital. The audit tools include demographic details, duration from onset of symptoms (self-reported) to first injection, time from first diagnosis at primary care to first treatment, baseline best corrected visual acuity (ETDRS letters), quantitative and qualitative OCT findings, clinical features as noted by slit lamp biomicroscopy examination, lesion subtype and lesion size noted on fundus fluorescein angiography (FFA). The use of ICGA is optional in our clinic, but all the 5 patients in this report had ICGA to rule out PCV.

Each patient received 3 loading doses of monthly intravitreal ranibizumab $(0.5 \mathrm{mg}$ in $0.05 \mathrm{~mL})$ therapy and then went on to an OCT guided treatment schedule. The retreatment criteria were a drop in visual acuity associated with intra-retinal or sub-retinal fluid on OCT, new or persistent fluid or the presence of new hemorrhage or angiographic evidence of increase in lesion size (FFA was done at the discretion of the treating clinician).

\section{Case I}

A 71-year-old female presented with a 3-week history of decreased vision in the right eye. She was amblyopic in the left eye. The presenting visual acuity was 60 ETDRS letters in the right eye and 2 ETDRS letters in the left eye. Slit lamp biomicroscopic evaluation of the right eye revealed large areas of confluent soft drusen associated with a central 2 disc diameter area of sub-retinal fluid surrounded by hemorrhage. The left eye showed an optic nerve coloboma with confluent drusen at the posterior pole. Angiography (FFA and ICGA) showed a $100 \%$ classic $\mathrm{CNV}$. The patient received 3 monthly injections of ranibizumab which stabilized her vision to 60 letters. Reactivation was noted at the fifth month with fresh subretinal hemorrhage and she received 2 further injections of ranibizumab at fifth and ninth months. Since then her vision has remained stable at 60 letters and clinically, the macula remained dry with juxtafoveal subretinal fibrosis at 12 months follow-up (Figure 3).

\section{Case 2}

A 73-year-old female presented with a four week history of distorted vision in her left eye. She had a history of disciform scar in the right eye for the previous 5 years. The visual acuity was 24 ETDRS letters in the left eye and eight ETDRS letters in the right eye. Slit lamp biomicroscopy showed a pigment epithelial detachment (PED) in the left eye of about 2 disc diameters with extra-foveal hemorrhage. The right eye showed a macular disciform scar. Angiogram (FFA and ICGA) confirmed subfoveal occult CNV in the left eye. She had 3 injections of ranibizumab and her vision stabilized at 25 letters. Reactivation of the lesion indicated by new subretinal fluid was noted at the sixth month follow-up (Figure 1). She received 2 more injections of ranibizumab at the sixth and seventh months. At the final follow up of 12 months, her vision was stable at 25 letters and the lesion was dry with central subretinal fibrosis (Figure 2).

\section{Case 3}

A 75-year-old male was referred from his optician with a history of hemorrhage at the posterior pole in the left eye. He had a history of disciform scar in his right eye. The presenting visual acuity was 45 letters in the left eye and 25 letters in the right eye. Examination of the left eye revealed a large area of juxtafoveal subretinal bleed while the right eye showed a macular disciform scar. Angiogram (FFA and ICG) confirmed the presence of a subfoveal occult CNV partly obscured by the hemorrhage with no evidence of IPCV. The patient received 3 injections of ranibizumab in the left eye. His vision is stable at 40 letters and clinically, the hemorrhage has resolved leaving a large area of retinal pigment epithelial atrophy and central subretinal fibrosis at 12 months.

\section{Case 4}

An 82-year-old male was referred from the ERS (emergency referral service) with history of distorted vision in the left eye of 3 weeks duration. He had past history of disciform macular scar in the right eye. His presenting visual acuity was 45 letters in the left eye and 40 letters in right eye. Slit

Table I Summary of patient characteristics

\begin{tabular}{lllllll}
\hline Age/Sex & Presenting VA & VA final & Type of CNV & Lesion size (DD) & Number of injections & Other eye \\
\hline $71 / \mathrm{F}$ & 60 & 60 & Classic & $2 \mathrm{DD}$ & 5 & Amblyopia \\
$73 / \mathrm{F}$ & 24 & 25 & Occult & $2 \mathrm{DD}$ & Disciform \\
$76 / \mathrm{M}$ & 45 & 40 & Occult & IODD & 5 & Disciform \\
$82 / \mathrm{M}$ & 45 & 45 & Occult & 5DD & 3 & Disciform \\
$84 / \mathrm{F}$ & 60 & 47 & Predominantly classic & $6 \mathrm{DD}$ & 3 & Disciform \\
\hline
\end{tabular}

Abbreviations: M, male; F, female; CNV, choroidal neovacularization; DD, disc diameters; VA, visual acuity. 


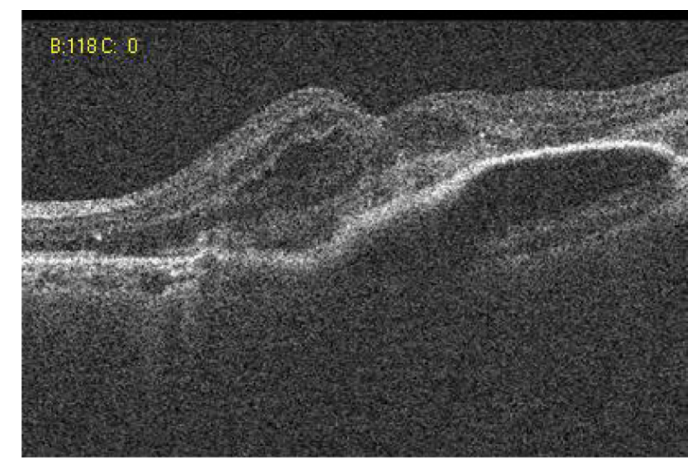

Figure I Case 2: Pre-ranibizumab therapy: Cirrus OCT macular cube $(512 \times 128)$ showing intra-retinal fluid.

lamp biomicroscopy showed an area of 5 disc diameters of RPE atrophy at the posterior pole with a streak of subretinal juxtafoveal hemorrhage extending across the atrophic area in the left eye. The right eye showed a macular disciform scar. The angiogram (FFA and ICGA) confirmed a subfoveal occult CNV of about 5 disc diameters. He had three consecutive injections of ranibizumab in the left eye for 3 months and was subsequently observed monthly. At 6 months follow-up reactivation was seen with fresh hemorrhages noted at the macula and he received a fourth injection of ranibizumab. His vision is stable at 45 letters and clinically an atrophic lesion with subretinal fibrosis is present at 12 months follow up.

\section{Case 5}

An 84-year-old female presented with a history of reduced vision in the right eye of 2 weeks duration. She had a history of blindness in the left eye since 30 years, secondary to idiopathic extensive chorioretinal scarring. The presenting visual acuity was 60 letters in the right eye and no projection of light in the left eye. Slit lamp biomicroscopy showed a large

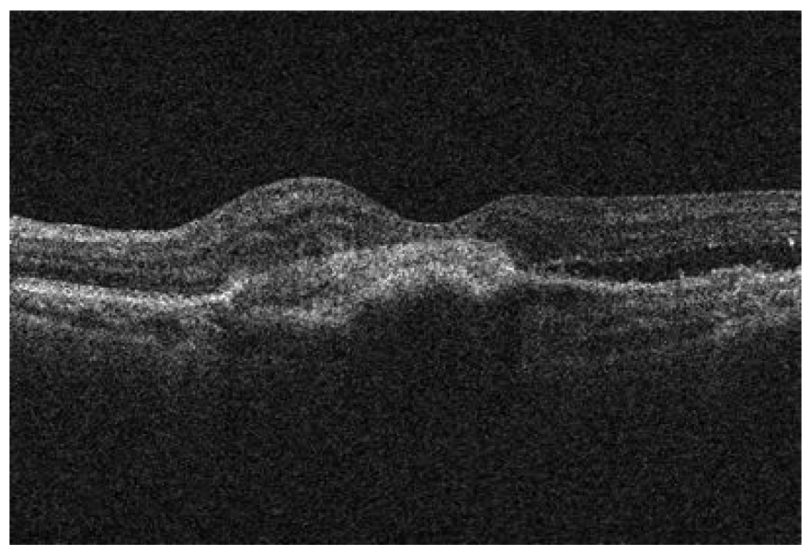

Figure 2 Case 2: Post-ranibizumab therapy: Cirrus OCT macular cube $(512 \times 128)$ showing sub-retinal fibrosis and foveal atrophy.

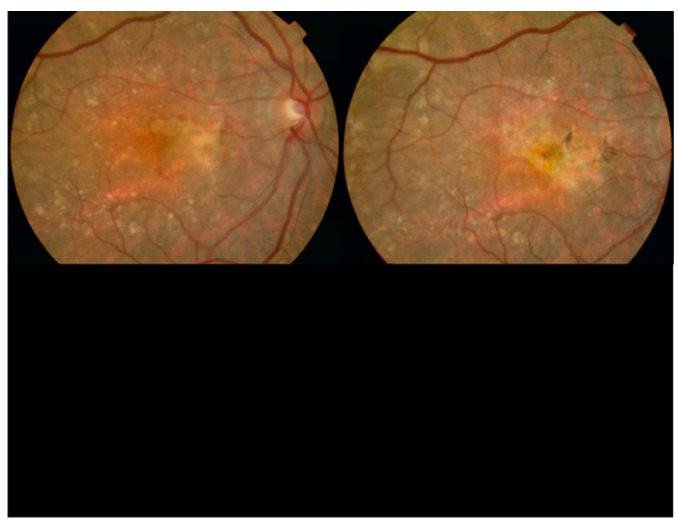

Figure 3 Pre- and post-ranibizumab therapy showing increase in macular fibrosis.

area of confluent soft drusen extending up to the vascular arcades with a central 6 disc diameter area of subretinal fluid with areas of subretinal hemorrhages. Angiogram confirmed predominantly classic CNV. The patient received 3 injections of ranibizumab but the lesion was still active with subretinal fluid on OCT scan. She continued to receive nine further injections monthly. She had persistent subretinal fluid and her vision was 47 letters at 12 months follow up.

\section{Discussion}

This study is not a population-based prevalence or incidence study, but a report on the number of black patients who have actually been treated with ranibizumab in our Medical Retina Clinic (Table 1). Our audit database shows that approximately 450 persons per million populations require ranibizumab therapy in South East London. While these figures may be an underestimate due to patients presenting late or presenting at other units, we believe that it reflects the proportion of treatable patients presenting to most treatment centers in the UK at present.

London has a multiethnic population. Lambeth, Southwark, and Lewisham are the three adjacent boroughs in inner London with a combined population of about 737,000 (the total population of London is around 7 million) where $25 \%$ of the population are made up of black Caribbean, black African and black other $(n=184,000)$. However, only $16 \%$ of the black population are above 55 years. Patients from this area are referred to King's College Hospital for secondary care.

Our audit data indicate that 5 out of 350 patients $(0.014 \%)$ undergoing ranibizumab therapy for neovascular AMD are blacks. These figures suggest a prevalence data of $0.03 \%$ of blacks requiring ranibizumab therapy for neovascular AMD (these data does not include patients that present with PCV). This low rate of presentation may be because of the reported 
low prevalence of AMD in the blacks, lower proportion of older blacks in these London boroughs and lack of awareness of the disease.

The audit of our ranibizumab database showed that 94\% of the patients showed stabilization of vision (loss of 15 ETDRS letters or less) while $18 \%$ gained 15 or more ETDRS letters at 12 months. In comparison, the results in black patients suggest that although stabilization of visual acuity is achieved in $100 \%$, none of the black patients gained vision. It is also important to note that despite the robust re-treatment criteria, these patients did not require many injections. However, subretinal fibrosis was seen in all cases from the third injection. In addition, extended areas of retinal pigment atrophy were noted in two areas. We hypothesize that exaggerated subretinal fibrosis and retinal pigment epithelial atrophy in blacks may represent part of the spectrum of increased tendency of hypertrophic dermatologic scars in black people. These scars are associated with increased serum levels of cytokines such as IL- 6 , TGF- $\beta$ and TNF- $\alpha$, upregulation of tumour suppressor gene p53 and anti-apoptotic gene Bcl-2 and low levels of vitamin D3. ${ }^{7}$ It may be useful to study the role of inflammation and apoptosis related genes to better understand the pharmacogenetics of neovascular AMD in the black population. ${ }^{8}$

All the five patients also had poor vision in the other eye, four of them due to disciform macular scars following wet AMD and one due to amblyopia. The amblyopic eye also had confluent drusen at the macula. It is interesting to note that none of these patients had retinal angiomatous proliferation.

Ranibizumab was well-tolerated in this group. ${ }^{9}$ Although glaucoma is common in the black community, none of these patients had the condition or experienced post-injection spikes of raised intraocular pressure. ${ }^{10,11}$ However, the observations in our small case series are retrospectively obtained, limiting the generalization of these findings. These observations should prompt larger prospective studies to evaluate the response of this therapy in various ethnic groups.

\section{Disclosure}

S Sivaprasad has received travel grants, research grants and participated in advisory board meetings for Pfizer, Novartis and Allergan.

\section{References}

1. Amoaku WM. The Royal College of Ophthalmologists interim recommendations for the management of patients with age-related macular degeneration. Eye. 2008;22:864-868.

2. Klein R, Klein BE, Cruickshanks KJ. The prevalence of age-related maculopathy by geographic region and ethnicity. Prog Retin Eye Res. 1999;18:371-389.

3. Klein R, Klein BE. Prevalence of Age-Related Macular Degeneration in 4 Racial/Ethnic Groups in the multi-ethnic study of atherosclerosis. Ophthalmol. 2006;113:373-380.

4. Sho K, Takahashi K, Yamada H, et al. Polypoidal Choroidal Vasculopathy Incidence, demographic features, and clinical characteristics. Arch Ophthalmol. 2003;121:1392-1396.

5. Rosenfeld PJ, Brown DM. Ranibizumab for Neovascular Age-Related Macular degeneration. N Engl J Med. 2006;355:1419-1431.

6. Brown DM, Michels M, Kaiser PK, Heier JS, Sy J, Ianchulev T. Ranibizumab versus Verteporfin Photodynamic Therapy for Neovascular Age-Related Macular degeneration: Two-Year Results of the ANCHOR Study. Ophthalmol. 2009;116:57-65.

7. Cooke GL,Chien A, Brodsky A, Lee RC. Incidence of hypertrophic scars among African Americans linked to vitamin D-3 metabolism? J Natl Med Assoc. 2005;97:1004-1009.

8. Do DV. Antiangiogenic approaches to age-related macular degeneration in the future. Ophthalmology. 2009 Oct;116 Suppl 10:S24-S26.

9. Spitzer MS, Ziemssen F, Bartz-Schmidt KU, Gelisken F, Szurman P. Treatment of age- related macular degeneration: focus on ranibizumab. Clin Ophthalmol. 2008;2:1-14.

10. Schmidt-Erfurth U. Clinical safety of ranibizumab in age-related macular degeneration. Expert Opin Drug Saf. 2010;9:149-165.

11. Georgalas I, Papaconstantinou D, Tservakis I, Koutsandrea C, Ladas I. Severe hypotony and filtering bleb leak after intravitreal injection of ranibizumab. Ther Clin Risk Manag. 2009;5:17-19.
Clinical Ophthalmology

\section{Publish your work in this journal}

Clinical Ophthalmology is an international, peer-reviewed journal covering all subspecialties within ophthalmology. Key topics include: Optometry; Visual science; Pharmacology and drug therapy in eye diseases; Basic Sciences; Primary and Secondary eye care; Patient Safety and Quality of Care Improvements. This journal is indexed on Submit your manuscript here: http://www.dovepress.com/clinical-ophthalmology-journal

\section{Dovepress}

PubMed Central and CAS, and is the official journal of The Society of Clinical Ophthalmology (SCO). The manuscript management system is completely online and includes a very quick and fair peer-review system, which is all easy to use. Visit http://www.dovepress.com/ testimonials.php to read real quotes from published authors. 